\title{
Acute Hyperuricemia Secondary to Epileptic Seizures Leading to Acute Urate Nephropathy: A Case report
}

\author{
Khalid Shahzad ${ }^{1}$, Mudassira Ghulam Nabi ${ }^{1}$, Anum Ashfaq ${ }^{1 *}$, Irshad Khan ${ }^{2}$, Asim Anwar ${ }^{2}$, Abdul \\ Hameed Jmali ${ }^{2}$ and Yasir Saadat ${ }^{2}$ \\ ${ }^{1}$ Resident General Medicine, Pakistan Atomic Energy Commission General Hospital, Pakistan
}

${ }^{2}$ Consultant General Medicine, Pakistan Atomic Energy Commission General Hospital, Pakistan

*Corresponding author: Anum Ashfaq, Resident General Medicine, Pakistan Atomic Energy Commission General Hospital, Islamabad, Pakistan

\begin{tabular}{|c|c|}
\hline ARTICLE INFO & ABSTRACT \\
\hline Received: 㗀 August 28, 2021 & $\begin{array}{l}\text { Almost } 75 \% \text { of the uric acid produced by the body is eliminated by kidney while } \\
\text { the remaining } 25 \% \text { is cleared by intestines. Blood levels of uric acid is maintained by }\end{array}$ \\
\hline Published: 蔧 September 20, 2021 & $\begin{array}{l}\text { balance between breakdown of purines and rate of urate excretion. Rare causes of acute } \\
\text { hyperurice1mia include rhabdomyolysis, strenuous exercise and fits. Acute hyperurice- }\end{array}$ \\
\hline $\begin{array}{l}\text { Citation: Khalid Shahzad, Mudassira } \\
\text { Ghulam Nabi, Anum Ashfaq, Irshad Khan, } \\
\text { Asim Anwar, et al., Acute Hyperuricemia } \\
\text { Secondary to Epileptic Seizures Leading } \\
\text { to Acute Urate Nephropathy: A Case re- } \\
\text { port. Biomed J Sci \& Tech Res 38(5)-2021. } \\
\text { BJSTR. MS.ID.006215. }\end{array}$ & $\begin{array}{l}\text { mia can lead to acute kidney injury. This is a case of } 35 \text {-year-old male with no premor- } \\
\text { bid who presented with generalized tonic clonic fits. At presentation patient was vitally } \\
\text { stable. He had two such episodes in last } 30 \text { minutes. After controlling the seizures with } \\
\text { intravenous antiepileptics all his baseline investigations were sent. Complete blood pic- } \\
\text { ture showed leukocytosis. Liver function tests, Renal function tests, C-reactive protein, } \\
\text { Erythrocyte sedimentation rate, Serum electrolytes, Serum calcium, magnesium and } \\
\text { phosphorus were also normal. CPK levels were 153. Serum uric acid was } 20.73 \mathrm{mg} / \mathrm{dl} \text {. } \\
\text { Chest x-ray, Electrocardiography and Echocardiography were normal. After } 2 \text { days Renal }\end{array}$ \\
\hline $\begin{array}{l}\text { Keywords: Hyperuricemia; Generalized } \\
\text { tonic clonic fits; Acute kidney injury }\end{array}$ & $\begin{array}{l}\text { function tests started deranging with maximum levels of Urea } 55 \mathrm{mg} / \mathrm{dl} \text { and creatinine } \\
2.88 \mathrm{mg} / \mathrm{dl} \text {. Patient was managed with intravenous hydration and allopurinol. His renal } \\
\text { function tests and uric acid levels normalized completely after } 6 \text { days. }\end{array}$ \\
\hline
\end{tabular}

\section{Background}

About two third of the body uric acid is produced endogenously while the rest of one third is from dietary products containing purines. Most of the uric acid is excreted through kidneys while the remaining through intestines. Hyperuricemia occurs either due to underexcretion of urate or overproduction of urate. Factors that predominantly effect uric acid excretion include tubular fluid $\mathrm{Ph}$, tubular fluid flow rate and renal blood flow. Acute hyperuricemia can lead to acute uric acid nephropathy by renal tubular obstruction by urate and uric acid crystals which can lead to significant morbidity. Seizures is an exceedingly uncommon cause of acute hyperuricemia. This is one such case of a patient with Generalized tonic clonic fits leading to acute hyperuricemia which in turn caused acute urate nephropathy.

\section{Case Presentation}

A 35-year-old man with no premorbid presented in emergency department with generalized tonic clonic fits. At presentation patient had Bp of 130/70, Pulse 96, Temperature 98.7F, Oxygen saturation $97 \%$ with room air. Blood sugar random was $126 \mathrm{mg} / \mathrm{dl}$. He had two such episodes in last 30 minutes. Abortive therapy was given to control the fits. After initial management detail examination was done. Central nervous system examination was normal with no focal neurological deficit. Chest was clear bilaterally with rest of respiratory examination normal. Cardiovascular, Gastrointestinal and musculoskeletal examination was also normal. Complete blood picture showed leukocytosis with white blood cell count 
$22550 /$ microliter with $80 \%$ neutrophils. Liver function tests, Renal function tests, C-reactive protein, Erythrocyte sedimentation rate, Serum electrolytes, Fasting lipid profile, Serum calcium, magnesium and phosphorus were also normal. Urine routine examination was normal with no myoglobinuria. CPK levels were 153 and serum prolactin levels were 404 . Serum uric acid was $20.73 \mathrm{mg} / \mathrm{dl}$. Chest x-ray, Electrocardiography and Echocardiography were normal. After 2 days his Renal function tests started deranging with Urea $45 \mathrm{mg} / \mathrm{dl}$ and creatinine $1.52 \mathrm{mg} / \mathrm{dl}$. His previous renal function tests and uric acid were completely normal. Maximum urea and creatinine levels went up to 55 and $2.88 \mathrm{mg} / \mathrm{dl}$ respectively. Patient was managed with intravenous hydration and allopurinol. His renal function tests and uric acid levels started declining and normalized after 5 days.

\section{Discussion}

In previous case studies it was noted that creatinine was deranged initially on the day of presentation. In our case unusual was that patient's creatinine was normal at presentation and started rising after 2 days. So, it is important to follow patient's Renal function tests for at least 4-5 days post seizure so that acute renal failure is not missed which can prove fatal if not managed early. Secondly in previous studies maximum level of high uric acid levels were up to $15 \mathrm{mg} / \mathrm{dl}$ while in our case serum uric acid was extremely high with levels up to $20.73 \mathrm{mg} / \mathrm{dl}$ which was managed successfully with early intervention.

Uric acid is the final insoluble waste product of purine breakdown [1]. Uricase enzyme which allows converts insoluble uric acid to soluble allantoin in absent in humans because of which it accumulates in the distal part of nephron particularly in acidic environment leading to toxicity [1,2]. Multiple studies have proven that high uric acid level is linked with many systemic illnesses including hypertension, chronic kidney disease, cardiovascular disease, diabetic nephropathy, stroke and acute kidney injury $[3,4]$. Tumor lysis syndrome is the most common cause of acute hyperuricemia through high cell turnover and cell lysis following aggressive chemotherapy for cancer particularly lymphoma $[1,2]$. When urinary uric acid surpasses solubility threshold, it is deposited and accumulated as crystals in renal tubule leading to acute renal failure [2]. High uric acid levels have been implicated to change the basic architecture of renal histology and have an important role in acute and chronic renal injury [5].

Acute uric acid nephropathy is characterized by raised creatinine levels; high uric acid levels raised urinary urate to creatinine ratio [6]. High uric acid causes acute urate nephropathy by various mechanisms including uric acid crystal formation and non-crystal mediated pathway [6]. Acute urate nephropathy must be suspected in high risk patients who develop acute renal failure with high serum uric acid levels and presence of urate crystals in urinary sediment [2]. Various mechanisms proposed in the development of acute kidney injury secondary to hyperuricemia include uric acid crystal formation in tubules, renal vasoconstriction, endothelial dysfunction, stimulation of inflammatory response, oxidative stress, antiangiogenic changes and direct microvascular injury [6].

Acute uric acid nephropathy is reversible [1]. Epileptic fits cause skeletal muscle breakdown which in turn causes life threatening rhabd omyolysis leading to acute kidney injury in 15\% of patients [7]. Rhabdomyolysis releases high amount of myoglobin by breakdown of muscle cells which in turn results in high serum myoglobin levels. Raised serum myoglobin levels exceeds haptoglobin binding capacity resulting in myoglobinuria which causes cast formation and tubular obstruction leading to acute kidney injury [7].

Various metabolic abnormalities have been associated with severe epileptic seizures including lactic acidosis, raised ammonia, raised creatine phosphokinase and high prolactin levels [2]. Rare metabolic derangements associated with seizures include electrolyte changes, hyperuricemia and osmolality changes [2]. Fits induced hyperuricemia is one of the rarest complications described in literature even more rare when associated with acute urate nephropathy [2]. Seizures cause acute uric acid nephropathy by increasing uric acid levels and provide favorable environment for urate crystal formation [6].

It is speculated that acute hyperuricemia secondary to seizures occurs both due to overproduction and impaired tubular excretion of urate [1]. Muscle injury during seizures causes tissue breakdown which release nucleosides leading to its transport into liver and is converted into uric acid by urea cycle [6]. Factors that lead to hyperuricemia following fits include acidification of urine secondary to acidosis caused by lactate production and hypoventilation making urate less soluble, dehydration secondary to hyperthermia and profuse diaphoresis causing increase tubular water reabsorption leading to high tubular uric acid secretion and renal ischemia due to shunting of blood from viscera to muscles [2].

Most effective therapy to lower uric acid levels is Rasburicase which is a recombinant form of xanthine oxidase [2]. Allopurinol inhibits uric acid formation, but it does not remove already existing urate in the body and may also worsen acute renal injury by releasing xanthine [1]. Urinary alkalization can increase urate solubility but has not yet been proven to be effective in acute urate nephropathy [1]. Oliguria secondary to acute urate nephropathy have excellent response to hemodialysis [1].

\section{Conclusion}

In nutshell acute hyperuricemia is an uncommon manifestation following a seizure. Immediate necessary steps should be taken to lower uric acid levels. Acute uric acid nephropathy is a reversible condition and if early management is done to lower urate levels it 
can prevent progression to acute renal failure with excellent fruitful outcome.

\section{Conflict of Interest}

No conflict of interest with any institution/organization.

\section{Grant or Fellowship Supporting the Writing of} Paper

Nil.

\section{Institutional Approval}

institutional approval was obtained in compliance with regulation of our institution and generally accepted guidelines governing such work.

\section{Processing Fee}

Nil.

\section{Author's Contribution}

Author fulfilling the ICMJE criteria.

ISSN: 2574-1241

DOI: $10.26717 /$ BJSTR.2021.38.006215

Anum Ashfaq. Biomed J Sci \& Tech Res

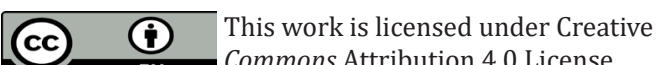

Submission Link: https://biomedres.us/submit-manuscript.php

\section{References}

1. Patel C, Wilson CP, Ahmed N, Hattab Y (2019) Acute Uric Acid Nephropathy following Epileptic Seizures: Case Report and Review. Case Rep Nephrol.

2. Côté JM, Bérubé AA, Bollée G (2020) Association of Hyperuricemia with Acute Kidney Injury: Case Series Report Among Patients Hospitalized with General Tonic-Clonic Seizures. Can J Kidney Health Dis.

3. Srivastava A, Palsson R, Leaf DE, Higuera A, Chen ME, et al. (2019) Uric Acid and Acute Kidney Injury in the Critically Ill. Kidney Med.

4. Ejaz AA, Johnson RJ, Shimada M, Mohandas R, Alquadan KF, et al. (2019) The Role of Uric Acid in Acute Kidney Injury. Nephron.

5. Giordano C, Karasik O, King-Morris K, Asmar A (2015) Uric Acid as a Marker of Kidney Disease: Review of the Current Literature. Dis Markers.

6. Makki N, Hajj G, Schmidt GA (2013) Seizure-induced acute urate nephropathy: case report and review. Chest.

7. Wang L, Hong S, Huang H, Yang M (2018) Rhabdomyolysis following status epilepticus with hyperuricemia: A case report and literature review. Medicine (Baltimore).

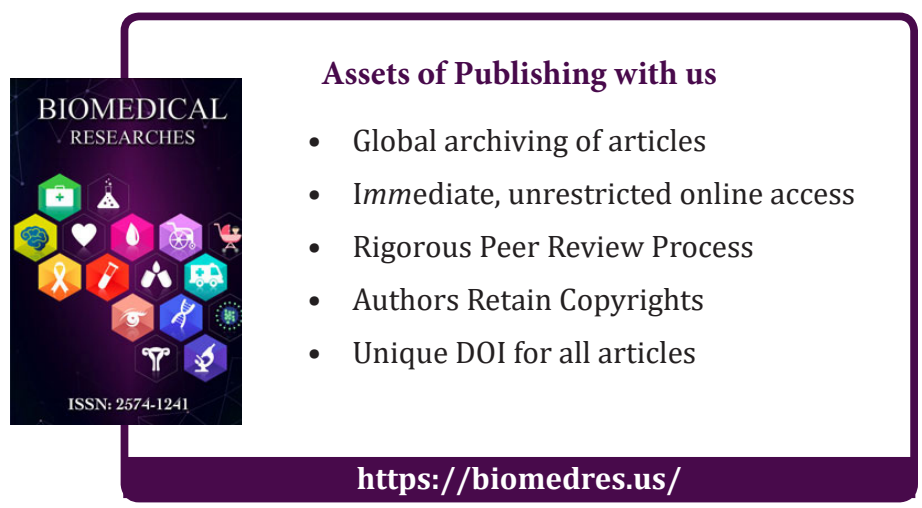

